\title{
An opportunity of new biomass materials as renewable energy in Thailand: perspective of coconut farmer
}

\author{
Pichet Ninduangdee ${ }^{\mathrm{a}}$, Kittinun Boonrod ${ }^{\mathrm{b}}$, Yupin Yuenyong ${ }^{\mathrm{c}}$, \\ Awassada Phongphipat ${ }^{\mathrm{d}}$ \\ ${ }^{a}$ Faculty of Engineering and Industrial Technology, Phetchaburi Rajabhat University, Phetchaburi 76000,Thailand \\ ${ }^{b}$ Faculty of Humanities and Social Science, Phetchaburi Rajabhat University, Phetchaburi 76000,Thailand \\ ${ }^{c}$ Faculty of Education, Phetchaburi Rajabhat University, Phetchaburi 76000,Thailand \\ ${ }^{d}$ The Joint Graduate School of Energy and Environment, King Mongkut's University of Technology, Bangkok 10140, Thailand
}

\begin{abstract}
This survey research aimed at examining perspective of coconut farmers on a feasibility of using biomass materials from coconut plantations for energy production. This research employed the Cochran Method to set the sample size with a confidence level of $95 \%$. The research went into the field to conduct the survey with questionnaires in 200 coconut farmers in Phetchaburi Province and Prachuap Khiri Khan Province where 0.07 million hectare of coconuts are grown, or $31 \%$ of all coconut plantations in Thailand. According to the main findings, raw materials in the form of leftover coconut biomass are composed of outer coat, middle fibrous cat, shell, upper core leave stalk, frond, bottom core leave stalk and empty fruit bunch. Upper core leave stalks are raw materials that have attracted the greatest interest in gathering as raw materials, whereas shell has attracted the least interest. The findings revealed that fruit peeling yards are the people best suited for compiling and buying raw materials. In terms of obstacles to gathering, material price uncertainty was found to be a major obstacle in gathering materials and was correlated opposite to interest in gathering upper core leave stalks with statistical significance.
\end{abstract}

Keywords: coconut residues, biomass, public perspective, renewable energy

\section{Introduction}

In Thailand, over $60 \%$ of the primary energy demand is covered by the energy imports. Since local fossil fuels and hydropower resources are limited, the country has developed a roadmap named as the "Renewable and Alternative Energy Development Plan (AEDP 2012-2021)" aiming at a substantial (by 25\%) increase of energy production from domestic alternative energy resources within the nearest ten years. According to this plan, an installed capacity of biomass-fuelled power generating facilities is expected to increase up to $3600 \mathrm{MW}_{\mathrm{e}}$ by the year 2021 [1].

Coconut is one of major economic crops in Thailand, and this crop is planted and cultivated mainly in South and Western regions of this country. Currently, Western region of Thailand has a total coconut plantation area of 0.08 million hectares, corresponding to $40 \%$ of the country's coconut plantation areas. Focusing on the provinces in the Western Thailand, Prachuap Khiri Khan and Phetchaburi Province are major coconut producers having 0.07 million hectares in coconut plantation area $(88 \%$ of the total plantation area of the Western Thailand), producing 0.28 ton of coconut equivalent to 31 percent of national output [2].

A significant amount of various residues and wastes (leave stalk, empty fruit bunch, frond, and husk) is generated during cultivation of coconut, As reported by Ref. [3], the heating value of coconut residues is relatively high (15.40-17.93 MJ/kg), comparable to some commercial biomasses [4-6] currently used

\footnotetext{
* Manuscript received March 12, 2018; revised June 23, 2019.

Corresponding author. E-mail address: ninduangdee.p@gmail.com

doi: $10.12720 /$ sgce.8.5.586-591
} 
as fuel in heat/power production in Thailand. Due to this fact, coconut residues are regarded as a promising resource of renewable energy for small-scale heat and power plants in this country. However, the coconut biomasses are not widely used as alternative fuel yet, mainly due to some constrains, particularly from perspective of coconut framers.

The conceptual framework of the present research has been set with the goal of studying a feasibility of using residues/wastes from coconut fields as biomass fuel, concerning on the viewpoints of coconut farmers of collecting each material. Factors on incentive and obstacles to gathering the biomass as well as approaches to gathering the biomass in the future are concerned in this work.

\section{Methodology}

\subsection{Scope of the study and research tool}

The studied areas in this work are Phetchaburi and Prachuap Khiri Khan Provinces, both located in Western Thailand, where the plantation area is approximately $35 \%$ of total area of country, and the collective production capacity is approximately $31 \%$. The selected biomass materials including fruit bunch, leave stalks, and fruits were studied. Note that only tall coconut trees that produce fruit for making coconut milk were focused in this work.

A sample size was set by the Cochran Method [7] with confidence level of 95\%. A research team conducted an on-field survey using 200 questionnaires with open- and close-ended questions interviewed the selected coconut farmers covering both provinces. The data was collected during January to June 2017. The questionnaire was submitted to the process of examination for accuracy by experts and tested for instrument reliability before conducting the real survey. The g Cronbach's Alpha Coefficient resulted in a reality score of 0.78 . By using the designed questionnairereliability analysis by using, the characteristics of residue/waste in the coconut field and opinions of coconut farmers regarding to using those residues as biomass energy were examined.

The study of opinions was composed of 6 topics with 29 questions as follows: 1) Degree of willingness to gather the raw materials (WILLIN); 2) Approaches to gather the leftover materials (APPROCH); 3) Direct incentive for gathering (INCENT); 4) Indirect incentive for gathering (IN_INCENT); 5) Perception on opportunity and participation (OPPOR), and 6) Obstacles to gather (OBSTAC). The 5 levels Likert Scale was applied in the analysis, where each of the range was marked as $<1.80$ (lowest), 1.81-2.60 (low), 2.61-3.40 (moderate), 3.41-4.20 (high), and 4.21-5.00 (highest).

\subsection{Data analysis}

The data obtained from questionnaire and interview was analysed using descriptive analysis with the following statistical values: percentage, mean and standard deviation. The data was then analysed with inferential statistics by using Pearson product moment correlation coefficient in order to find the correlations between the two variables. Testing the opinions on various issues led to planning by telling the degree or extent of the correlations by using the $R$ value. In cases where the $R$ value approached -1 or 1 , a high degree of correlation is indicated. If, however, the value is near 0 , a low degree of correlation or no correlation at all is indicated. A negative $R$ value indicates a correlation in the opposite direction, while a positive $R$ value indicated a correlation in the same direction.

\section{Results and Discussion}

\subsection{Coconut fruit bunch}

Coconut fruit bunch is created in two cases. The first case is naturally fallen coconut fruit bunches. The main factor is harvests of extremely tall coconut trees that require the use of monkeys to climb and pick fruits. The monkeys spin only coconut fruits to the ground while the bunch remains at the top and falls naturally when dry. The second case is by cutting products. This occurs with shorter coconut trees when fruits can be picked by using harvesting instruments, or when farmers can climb to pick fruits and cut coconut bunch before separating the fruits for sale. Empty fruit bunches are fresher than bunches that 
fall off naturally. According to a study of the volume produced per year, the findings revealed farmers were able to harvest a mean of 2.08 fruit bunches per time per tree with coconuts harvested at a mean of 10.92 times per tree per year. Empty coconut fruit bunches were left in the orchards $(94.23 \%)$, while the remaining fruit bunches were taken with fruits to peeling yards (5.77\%). In short, 22 empty coconut fruit bunch per tree will be left in orchards after harvest per year and one empty coconut fruit bunch per tree will be found at peeling yards per year, bringing the total number of empty coconut fruit bunches per year to 23 bunches per tree per year. Empty coconut fruit bunch currently has no commercial benefit other than burning dry parts to drive out insects or as household fuel

\subsection{Leave stalk}

Leave stalks extend from the tree as branches on ordinary trees. However, leave stalks are found only at the tops of coconut trees. Leave stalks are composed of the core attached to and encircled around trees like nail screws, while coconut leaves grow out from the core. Coconut leave stalks can be divided into three components as follows:

1) The upper core leave stalks (ULS) from where coconut leaves are attached to from the first leaf to the last leaf are left in orchards by some farmers. However, some farmers also gather upper core leave stalks from orchards because upper core leave stalks can generate income for farmers. When upper core leave stalks are fronded, they can be bought and used as fuel to make earthenware, particularly large earthen jars. Jar manufactories claim the fuel from this part of coconut cores exudes certain types of essential oils capable of coating jars or earthenware to create a sleek sheen. Upper core leave stalks are bought at 1-1.50 baht per stalk. A study of utilization ratios found upper core leave stalks to be used at $5.75 \%$

2) After farmers sell leave stalks to buyers, fronds (FRO) from the upper core leave stalks are used by cutting leaves with a knife, leaving only front cores for sale to buyers who take frond cores to make coconut brooms. Fronds have a mean selling price of $13-15$ baht per kilogram while some farmers sell fronds in bunches. Fronds are also burned to drive out insects. According to a study of frond utilization ratios, $11.13 \%$ of all fronds are used.

3) Bottom core leave stalks (BLS) are parts attached to the tree up to the first leave attached to upper core leave stalks. In other words, bottom core leave stalks are leftover materials form upper core leave stalk sales. Buyers claimed to not purchase this part due to moisture and because transport is difficult if this part is not removed. Bottom core leave stalks currently have no commercial value with only dry parts burned to drive out insects or household use. According to a study of frond utilization ratios, $4.80 \%$ of all bottom core leave stalks are used.

\subsection{Coconut fruit}

Biomass from coconut fruits consists of the three following types:

1) Outer Coat (OTC), OTC is created during peeling process, generally generated in a peeling yard. Most outer coat from fruit peeling yards and orchards is sold to coconut fiber factories. Sale prices are unstable. One truckload of $700 \mathrm{~kg}$ can have a price within the range of 3-25 US dollars, and large amounts of outer coats are left in piles when prices are low. However, if outer coats are considered for use in alternative energy production, doing so might be an opportunity to guarantee prices for farmers. According to the findings, $99.19 \%$ of all outer coats are used.

2) Middle Fibrous Coat (MFC) - Peeled coconut fruits with no outer coat are called soft fruits (in local language). Soft fruits are still covered by the middle fibrous coat. Coconut fruits are not peeled to the shell because the middle fibrous coat is required as a material for preventing impact during transportation. All middle fibrous coat material is currently disposed of with no commercial uses encountered.

3) Shell (SHE) - Major coconut peeling yards operate one-stop businesses from coconut fruit auctions at the orchard to peeling coconuts and selling coconut milk. However, most minor coconut peeling yards end their activities with coconut peeling. Some minor coconut peeling yards have continued to the "black fruit", meaning peeling coconut fruits to the shell, or the "white fruit", by scouring shells with blades to 
the white meat layer with the main by-product being shells. Charcoal briquette factories currently buy shells in pieces or as charcoal from shops and farmers who contract to burn charcoal. The findings revealed $91.30 \%$ of all coconut shells are used.

\subsection{Opinions of the farmers on using coconut residues as biomass energy}

Table 1 shows an analysis of factors correlated with willingness to gather materials, Based on the results in Table 1, the farmers have a high degree of WILLIN to gather materials at a mean of 3.58. ULS was the material with the highest level of willingness at a mean score of 4.52 points while, SHE was the lowest mean score at 2.40 points. This was because most shells are materials not directly possessed by farmers because most farmers sell all fruit products and shells were found only at fruit peeling yards.

According to a study on approaches for gathering leftover materials (see Fig. 1a), fruit peeling yards (MARK) were found to be the most suitable candidate as the gatherer and buyer of materials at a mean score of 3.81 points in the high zone, followed by independent sales and sales by GOVE at mean scores of 3.79 and 3.77 points, respectively, both of which were also in the high zone.

For INCENT (see Fig.1b), monetary and investment cost-efficiency incentives were found to be required by farmers if biomass is to be gathered at a mean score of 4.62 points in the highest zone. At the same time, IN_INCENT such as benefits for society or the environment were found to be in the moderate zone with a mean score of 3.56 points.

According to the findings regarding levels of OPPOR in operations in the overall view, farmers have awareness in the highest zone with a mean score of 4.32 points while opinions in the area of OBSTAC were in the low zone at a mean score of 2.17 points. Obstacles to material PRIC were found to be the main obstacle in material gathering when compared to other factors.


Fig.1. (a) score level for findings on material types and gathering guidelines and (b) incentives, opportunities for participation, and obstacles to gathering

\subsection{The analysis of factors correlated with willingness to gather materials}

When the analysis of factors correlated with willingness to gather materials were considered by analyzing the Pearson Product Moment Correlation Coefficient, OBSTAC and IN_INCENT were found to be correlated with willingness to gather materials with statistical significance at 0.01. OBSTAC Factor was correlated at the lowest level in the opposite direction $(R=-0.25)$, resulting in the interpretation that, when obstacles to gathering are reduced, willingness to gather materials will be higher. In the meantime, the IN_INCENT factor was correlated at the lowest level in the same direction as willingness to gather materials WILLIN $(\mathrm{R}=0.33)$. This can be interpreted as "in cases where farmers receive indirect incentives to create awareness of non-monetary incentives such as social or environmental benefits at a higher level, willingness to gather materials rises".

Table 1. Analysis of factors correlated with willingness to gather materials

\begin{tabular}{lllllll}
\hline \multirow{2}{*}{ Factor } & \multicolumn{2}{l}{ Descriptive Analysis } & \multicolumn{3}{l}{ Pearson Correlation Analysis } \\
\cline { 2 - 7 } & $\bar{x}$ & S.D. & Level & $\boldsymbol{R}$ - Value & Sig. & Relation \\
\hline INCENT & 4.62 & 0.18 & Highest & 0.01 & 0.88 & Lowest \\
IN_INCENT & 3.56 & 0.71 & Moderate & $0.33^{* *}$ & 0.00 & Low \\
OPPOR & 4.32 & 0.32 & Highest & -0.05 & 0.50 & Lowest \\
OBSTAC & 2.17 & 0.32 & Low & $-0.25^{* *}$ & 0.00 & Lowest \\
\hline WILLIN & $\mathbf{3 . 5 8}$ & $\mathbf{0 . 4 2}$ & High & $\mathbf{1 . 0 0}$ & - & - \\
\hline
\end{tabular}


Correlations were re-analysed by considering only correlated factors. OBSTAC and WILLIN received in-depth consideration of each minor issue. The factors correlated with obstacles to gathering consisted of LABO, TIME, INCO, STOR, and PRIC. Materials consisted of the seven following types: OTC, MFC, SHE, ULS, FRO, BLS, and EB. Table 2 shows analysis of factors correlated with obstacles and material types in gathering of coconut wastes. As seen in the data in Table 2, four types of materials have statistically significant correlations: OTC, MFC, SHE and ULS, all of which were correlated opposite to WILLIN. STOR were found to be the only obstacle not correlated to WILLIN with statistical significance. In the meantime, price uncertainty influenced the gathering of outer coats with significance while willingness to gather middle fibrous coat was correlated with labor factors at a high level.

Table 2. Analysis of factors correlated with obstacles and material types in gathering

\begin{tabular}{|c|c|c|c|c|c|c|}
\hline \multirow{2}{*}{ Categories } & \multirow{2}{*}{ Result } & \multicolumn{5}{|c|}{ Obstacle Factor } \\
\hline & & LABO & TIME & INCO & $\begin{array}{l}\text { STOR } \\
\end{array}$ & PRIC \\
\hline \multirow[t]{2}{*}{ OTC } & R - Value & $-0.15^{*}$ & $-0.16^{*}$ & -0.05 & -0.02 & $-0.30^{* *}$ \\
\hline & Relation & Lowest & Lowest & Lowest & Lowest & Low \\
\hline \multirow[t]{2}{*}{ MFC } & $\mathrm{R}$ - Value & $-0.70^{* *}$ & $-0.28^{* *}$ & 0.07 & -0.02 & -0.03 \\
\hline & Relation & High & Lowest & Lowest & Lowest & Lowest \\
\hline \multirow[t]{2}{*}{ SHE } & $\mathrm{R}$ - Value & $-0.29^{* *}$ & $-0.16^{*}$ & -0.01 & -0.11 & -0.08 \\
\hline & Relation & Lowest & Lowest & Lowest & Lowest & Lowest \\
\hline \multirow[t]{2}{*}{ ULS } & R - Value & 0.08 & -0.10 & $-0.16^{*}$ & -0.01 & -0.01 \\
\hline & Relation & Lowest & Lowest & Lowest & Lowest & Lowest \\
\hline \multirow[t]{2}{*}{ BLS } & R - Value & 0.04 & -0.04 & -0.09 & 0.02 & 0.01 \\
\hline & Relation & Lowest & Lowest & Lowest & Lowest & Lowest \\
\hline \multirow[t]{2}{*}{ FRO } & $\mathrm{R}$ - Value & 0.07 & 0.04 & -0.08 & -0.06 & -0.12 \\
\hline & Relation & Lowest & Lowest & Lowest & Lowest & Lowest \\
\hline \multirow[t]{2}{*}{ EB } & R - Value & 0.08 & 0.12 & 0.05 & 0.02 & 0.09 \\
\hline & Relation & Lowest & Lowest & Lowest & Lowest & Lowest \\
\hline
\end{tabular}

* Correlation is significant at the 0.05 level (2-tailed). ** Correlation is significant at the 0.01 level (2-tailed).

\section{Conclusion}

Residues from coconuts are composed of the outer coat, the middle fibrous coat, the shell, the upper core leave stalk, the frond, the bottom core leave stalk and empty fruit bunches. The upper core leave stalk is the material with the most interest for gathering, followed by the bottom score leave stalk, while the interested material was the shell. In terms of guidelines for gathering leftover materials, fruit peeling yards were found to be the most suitable candidates for gathering and buying materials, followed by independent material gatherers and sellers. Concerning gathering obstacles, material price uncertainty (PRIC) is found to be a major obstacle in gathering when compared to other factors. However, material price uncertainty was low. With regard to the factors correlated with willingness to gather materials, obstacles in gathering and indirect non-monetary gathering incentives such as social or environmental benefits are correlated with willingness to gather materials.

\section{Acknowledgements}

The authors would like to thank Energy Conservation Promotion Fund of Thailand (ENCON) as well as Phetchaburi Rajabhat University, Thailand for financial support.

\section{References}

[1] Department of Alternative Energy Development and Efficiency (June 8, 2015). The Renewable and Alternative Energy Development Plan for 25 Percent in 10 Years (AEDP 2012-2021) [online]. Available: http://www4.dede.go.th/dede/images/stories/pdf/dede_aedp_2012_21.pdf.

[2] Office of Agricultural Economics. Agriculture Statistic of Thailand 2015, Nation Office of Buddhism, 2016.

[3] Department of Alternative Energy Development and Efficiency (April 2, 2018), Biomass Potential of Thailand [Online]. Available: http://biomass.dede.go.th/biomass_web/index.html. 
[4] Ninduangdee P, Kuprianov VI, Cha EY. Kaewrath R, Youngyuen P. W. Atthawethworawuth, Thermogravimetric studies of oil palm empty fruit bunch and palm kernel shell: TG/DTG analysis and modelling. Energy Procedia, 2015; 79:453-458.

[5] Ninduangdee P, Kuprianov VI. Fluidized bed co-combustion of rice husk pellets and moisturized rice husk: The effects of cocombustion methods on gaseous emissions. Biomass and Bioenergy, 2018;112:73-84.

[6] Ninduangdee P, Kuprianov VI. Combustion of oil palm shells in a fluidized-bed combustor using dolomite as the bed material to prevent bed agglomeration. Energy Procedia,2014; 52:399-409

[7] Cochran, W.G. Sampling Techniques, 2nd ed. New York: John Wiley and Sons Inc; 1963. 